\title{
A relação terapêutica
}

Raquel Braga*

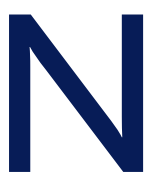

este espaço editorial da RPMGF, tenho vindo a falar de assuntos como a complexidadena especialidade de Medicina Geral e Familiar, ${ }^{1}$ ou como a sobrecarga de trabalho, com um número crescente de doentes e a pressão assistencial imposta pela necessidade de cumprir múltiplos indicadores de saúde, que pode comprometer a qualidade do trabalho. ${ }^{2}$ Falei, igualmente, da necessidade de praticarmos uma medicina baseada na evidência, que não se deve opor ao gut feelings, ${ }^{3}$ da necessidade de racionalizar e uniformizar a prática clínica, de forma a garantir equidade e eficácia nos actos médicos praticados pela nossa especialidade ${ }^{4} \mathrm{e}$ de muitos outros aspectos que nos consomem e preocupam enquanto médicos de família, como a falta de tempo para, com todos estes pressupostos, fazermos uma medicina de qualidade.

A propósito da conjunção de todos estes factores, é tempo de falar, agora, do mais importante, é tempo de centrar a atenção naquilo que nos levou (seguramente a muitos de nós) a sermos os médicos que hoje somos, a relação, que se espera que seja terapêutica.

Falo da presença balsâmica, da mão que cura ou alivia, do olhar que sossega e conforta.

Em termos menos poéticos ou literários, falo dessa relação impressionante que se estabelece entre o médico e o doente, que julgávamos ser parte da arte da Medicina e que hoje sabemos dever ser algo mais do que vocação ou dom inato. $^{5}$

Sabemos que o trabalho desenvolvido nessa relação deve ter, também, algo de aprendido, reflectido, discutido e treinado, algo incluído nas competências clínicas de um médico em formação pré ou pós-graduada. ${ }^{5}$ Foi documentado que esse treino de relação clínica tem consequências positivas nas competências comunicacionais observadas por observadores externos, e que um maior conhecimento sobre comunicação e auto-conhecimento (self-awareness) pode aumentar a auto-confiança do médico. ${ }^{6}$

A relação terapêutica baseia-se em inúmeros ingredientes. Um deles é a empatia, ou seja, a capacidade de compreender os sentimentos, os pensamentos e as atitudes do outro e de dar a entender ao outro que o compreendemos; este 'colocarmo-nos no lugar do outro' deve ser feito, no en-

*Directora da Revista Portuguesa de Medicina Geral e Familiar tanto, sem ultrapassarmos a fronteira da nossa identidade, sem sentirmos o mesmo que o outro sente e sem pensarmos o mesmo que o outro pensa, sob pena de estarmos a ser simpáticos e não empáticos. Outro será a confiança, que contempla a consideração e atenção pela individualidade e singularidade de cada um. Inclui-se nesta relação, para além do conhecimento biomédico para fornecer respostas nesse plano, a inteligência emocional que um médico deve ter em grande dose e usar na vida e na profissão, para que a sua presença e actuação tenha um efeito curativo ou reconfortante, bem como um efeito motivador, de controlo emocional e de adequação social. A inteligência emocional foi definida por Daniel Goleman como a «...capacidade de identificar os nossos próprios sentimentos e os dos outros, de nos motivarmos e de gerir bem as emoções dentro de nós e nos nossos relacionamentos». Enfoca a necessidade de auto-conhecimento pessoal (self-awareness). Realça a experiência em lidar com os sentimentos adequando-os a uma plêiade de situações vivenciadas (neste caso pelo próprio médico ou por este através dos olhos dos doentes, sendo o médico, por isso, um espectador privilegiado para apreender o mundo). Desencadeia naturalmente a interacção com os outros (que podemos denominar como connexional experience), ${ }^{8}$ que deverá colocar em relevo a sensibilidade ehabilidade sociais. A dose de inteligência emocional a utilizar na relação terapêutica deve ser regulada pelas necessidades manifestadas pelo doente, mas também pelas necessidades sentidas pelo próprio médico na gestão da relação. Não parece haver efeitos laterais em caso de sobredosagem deste ingrediente.

A relação médico-doente contempla a capacidade de entender o outro na sua linguagem verbal e não-verbal, nas suas expectativas, no seu contexto vivencial e nos seus receios. No entanto, não se esgota aqui, já que, para além de fazer perceber ao doente que é entendido, ajuda a lidar com a incerteza do diagnóstico, com a impotência perante a doença terminal, tornando esta ou outro tipo de experiências, que não têm respostas num modelo biomédico, mais compensadoras e menos frustrantes. ${ }^{8}$

$\mathrm{O}$ estabelecimento de um relacionamento terapêutico (muitas vezes assinalado por um momento especial de ligação, que geralmente ocorre nas chamadas «consultas sagradas») $)^{9}$ é uma tarefa clínica fundamental e pode assumir uma importância equivalente a qualquer outro tratamento 
curativo ou paliativo, não importando o tempo que a relação médico-doente vai durar (minutos ou anos). Todos nós já experienciámos esta situação, mesmo com doentes que acabámos de conhecer e sabemos o quão efectiva e real ela pode ser. Damos imediatamente conta, ou apercebemo-nos posteriormente que, episódica ou frequentemente, temos esse impacto relacional terapêutico na vida da pessoa que está perante nós.

Ao médico de família, pela relação de continuidade que mantém com os seus doentes, cabe, como na relação de amor que se inicia e reacende em momentos de paixão, saber pontuar a relação longitudinal de proximidade, incendiando-a de momentos de oportuna e efectiva proximidade e eficácia terapêutica, sempre que necessário ou requerido.

É um desejo da grande maioria dos seres humanos, sobretudo dos que estão ou se sentem doentes, obter este tipo de relacionamento terapêutico e procurar médicos que o proporcionem. Algumas vezes, estranhamente, buscam-no e encontram-no fora da medicina convencional, uma vez que nem todos os médicos cultivam ou exercem este tipo de relação. Nem todos os médicos investem ou conseguem investir nessa faceta de curador que há milénios atravessa as diversas culturas, tornando esta uma relação quase-mágica. Convém relembrar que a Medicina emergiu da cura ritual e religiosa e que, só nos últimos séculos, a ciência a foi separando desta interpretação religiosa da doença e do sofrimento.

No seio da classe médica observamos que, por vezes, quando esta forma de comunicação não é inata, quando descurada inadvertidamente ou posta em segundo plano pela assumpção de um relacionamente mais técnico, mais distante, mais centrado no próprio médico, ou menos atento e descentrado da relação, facilmente este efeito terapêutico não acontece na consulta e não surte o devido resultado tranquilizador ou terapêutico para o doente, causando insatisfação.

Paradoxalmente, a esta busca por parte da maioria dos doentes, que apesar de não se contentar somente com o conforto relacional, lhe atribui um enorme valor, opõe-se a percepção de alguns médicos de que o sucesso da sua intervenção depende apenas da cura ou, pelo menos, do controlo ou domínio das doenças, realização esta que muitas vezes está para além do alcance da medicina e independente dos dotes técnicos ou científicos do médico.

A importância de tomar consciência do poder que a relação terapêutica tem para o doente e para o médico (com- pensando-o, e prevenindo a exaustão, sobretudo em situações difíceis), ou seja, o sentido de a reconhecer, aprender, cultivar, desenvolver, trabalhar e ensinar é deveras impactante para ambos os elementos do binómio médico-doente.

A mudança do paradigma do modelo médico e de relação com o doente deve conduzir à manutenção de mudanças na educação médica. ${ }^{5,10}$ As competências no relacionamento com o doente deveriam ter o mesmo peso no ensino clínico que o ensino da anamnese, do exame físico e do raciocínio diagnóstico. Factores facilitadores do auto-conhecimento e do crescimento pessoal deveriam ser incluídos entre os objetivos declarados e assumidos no processo de educação médica. ${ }^{5}$

Cultivando o tempo, a técnica e a sensibilidade para isso, o facto de centrarmos a comunicação no doente e na relação terapêutica interferirá seguramente na qualidade da medicina que praticamos, tornando-a mais gratificante e eficaz.

\section{REFERÊNCIAS BIBLIOGRÁFICAS}

1. Braga R. Complexidade em Medicina Geral e Familiar. Rev Port Med Geral Fam 2013 Jan -Fev; 29 (1):82-4.

2. Braga R. Listas de 1900 utentes: a quantidade questiona a qualidade. Rev Port Med Geral Fam 2012 Set-Out; 28 (5): 331-2.

3. Braga R. Da evidência ao gut feelings. Rev Port Clin Geral 2011 Jul-Ago; 27 (4): 329-30.

4. Braga R. A crise económica e as boas práticas clínica. Rev Port Clin Geral 2011 Set-Out; 27 (5): 415-6.

5. Carvalho IP, Ribeiro-Silva R, Pais VG, Figueiredo-Braga M, Castro-Vale I, Teles A, et al. O ensino da comunicação na relação médico-doente: uma proposta em prática. Acta Med Port 2010 Mai-Jun; 23 (3): 52732.

6. Carvalho IP, Pais VG, Almeida SS, Ribeiro-Silva R, Figueiredo-Braga M, Teles A, et al. Learning clinical communication skills: outcomes of a program for professional practitioners. Patient Educ Couns 2011 Jul; 84 (1): 84-9.

7. Goleman D. Emotional intelligence. New York: Bantam Books; 1995.

8. Suchman AL, Matthews DA. What makes the patient-doctor relationship therapeutic? Exploring the connexional dimension of medical care. Ann Intern Med 1988 Jan; 108 (1): 125-30.

9. Gérvas J, Pérez Fernández M, Gutiérrez Parres B. Consultas sagradas: serenidad en el apresuramiento. Aten Primaria 2009 Ene; 41 (1): 41-4.

10. Spencer JA, Silverman J. Communication education and assessment: taking account of diversity. Med Educ 2004 Feb; 38 (2): 116-8.

\section{CONFLITO DE INTERESSES}

A autora não tem conflito de interesses.

ENDEREÇO PARA CORRESPONDÊNCIA

director@rpcg.apmcg.pt 